\title{
Fat and Fatty Acid Intake and Metabolic Effects in the Human Body
}

\author{
T.A.B. Sanders \\ Nutritional Sciences Division, King's College London, London, UK
}

\section{Introduction}

Dietary fat intake influences the physiological processes that transport fat between tissues as well as influencing the substrates for metabolic processes. Lipids need to be transported as lipoprotein complexes owing to the poor water solubility of lipids. Variations in plasma lipoprotein concentration influence the development of atherosclerosis. Atherosclerosis is the underlying pathological disorder underlying the major cardiovascular diseases (CVD; ischemic heart disease and ischemic cerebrovascular disease), which are leading causes of death worldwide. Clinical events usually result from the rupture of a plaque and subsequent thrombus formation. Elevated concentrations of apolipoprotein B100-containing lipoproteins (very-low-density lipoprotein (VLDL), intermediate-density lipoprotein and low-density lipoprotein (LDL)) are causally linked to the atherogenic process. Atherogenesis is a chronic inflammatory process that results from the accumulation of fatty streaks in large/medium arteries, which progress to form fibrous plaques over time [Ross, 1999]. The foam cells that constitute the initial lesion (the fatty streak) result from the uptake of apolipoprotein B100-containing proteins (mainly LDL) by tissue macrophages. Native LDL is not taken up by macrophages, but chemically modified (i.e., oxidated or glycated) apolipoprotein B100 is avidly taken up by the tissue macrophages, as are chylomicron rem- (c) 2009 S. Karger AG, Basel and FAO

0250-6807/09/0553-0162\$26.00/0

Accessible online at:

www.karger.com/anm nants, to form foam cells. There is convincing evidence that foam cells can progress to form fibrous atherosclerotic plaques. There is a large body of scientific evidence, both in animal models and corroborated by human observational and intervention studies, showing that dietary fat intake is causally involved in atherogenesis and may also influence arterial thrombosis. With regard to the experimental feeding studies in animals, the evidence is convincing that elevations of plasma lipids caused by modification of dietary fat intake result in atherosclerosis. These animal studies indicate that fats high in saturated (SFA), monounsaturated (MUFA) and trans fatty acids (TFA) promote atherosclerosis [Brown et al., 2007], whereas diets containing oils high in polyunsaturated fatty acids (PUFA) inhibit atherosclerosis and low-fat diets do not promote atherosclerosis. This review focuses on the evidence from dietary intervention studies in man that dietary fat intake influences metabolic factors associated with risk of CVD.

\section{Fasting Plasma Lipid and Lipoproteins and Dietary Fat Intake}

Plasma total cholesterol (TC) concentration shows a continuous association with CVD risk without a threshold, but with the absolute risk increasing with age, smoking habit and raised blood pressure [Lewington et al., 
Table 1. Summary of the change in serum lipids predicted from replacing $1 \%$ energy by individual fatty acids for carbohydrate based on the meta-analysis [adapted from EFSA, 2004] and changes from increasing intake of dietary cholesterol by $100 \mathrm{mg}$ based on analysis of Weggemans et al. [2001]

\begin{tabular}{lllll}
\hline & TC & LDL-C & HDL-C & TC:HDL-C \\
\hline Lauric acid (12:0) & $+0.069(0.040$ to 0.097$)$ & $+0.052(0.026$ to 0.078$)$ & $+0.027(0.021$ to 0.033$)$ & $-0.037(-0.057$ to -0.017$)$ \\
Myristic acid (14:0) & $+0.059(0.036$ to 0.082$)$ & $+0.048(0.027$ to 0.069$)$ & $+0.018(0.013$ to 0.023$)$ & $-0.003(-0.026$ to 0.021$)$ \\
Palmitic acid (16:0) & $+0.041(0.028$ to 0.054$)$ & $+0.039(0.027$ to 0.051$)$ & $+0.010(0.007$ to 0.013$)$ & $+0.005(-0.008$ to 0.019$)$ \\
Stearic acid (18:0) & $-0.010(-0.026$ to 0.006$)$ & $-0.004(-0.019$ to 0.011$)$ & $+0.002(-0.001$ to 0.006$)$ & $-0.013(-0.030$ to 0.003$)$ \\
Elaidic acid (18:1 trans $)$ & $+0.031(0.020$ to 0.042$)$ & $+0.040(0.020$ to 0.060$)$ & $0.000(-0.007$ to 0.006$)$ & $+0.022(0.005$ to 0.038$)$ \\
Oleic acid (18:1 cis $)$ & $-0.006(0.020$ to 0.042$)$ & $-0.009(-0.014$ to -0.003$)$ & $+0.008(0.005$ to 0.011$)$ & $-0.026(-0.035$ to -0.017$)$ \\
PUFA & $-0.021(0.020$ to 0.042$)$ & $-0.019(0.020$ to 0.060$)$ & $+0.006(0.007$ to 0.006$)$ & $-0.032(0.005$ to 0.038$)$ \\
Dietary cholesterol $\quad(+100$ mg/day) & $+0.056(0.046$ to 0.065$)$ & $+0.050(0.042$ to 0.058$)$ & $+0.008(0.042$ to 0.058$)$ & $+0.020(0.010$ to 0.030$)$ \\
\hline
\end{tabular}

Data presented in $\mathrm{mmol} / \mathrm{l}$ with $95 \% \mathrm{CI}$ in parentheses.

2007]. Reductions in TC and LDL concentrations with statin therapy convincingly lower CVD risk, but the effects on CVD risk reductions using other agents (drug or diet) are less well established. Elevated plasma lipoprotein $\mathrm{Lp}(\mathrm{a})$ is associated with increased CVD risk, especially when it is associated with elevated plasma LDL cholesterol (LDL-C) concentrations [Seed et al., 1990]. The relationship between fasting plasma triacylglycerol (TAG) concentration and CVD risk is more complex because it can be transiently changed by diet, alcohol intake and physical activity. However, prolonged elevation of plasma TAG, which is often associated with the insulinresistance syndrome and increased VLDL synthesis, generates small dense LDL particles (which are rich in apolipoprotein B relative to cholesterol) and causes a fall in high-density lipoprotein (HDL; measured as apolipoprotein A1 or HDL cholesterol (HDL-C)). This atherogenic dyslipidaemia (high TAG, small dense LDL-C and low HDL-C) is now recognized as conferring a substantial increase in CVD risk [Expert Panel on Detection, Evaluation, and Treatment of High Blood Cholesterol in Adults, 2001]. The ratio of TC:HDL-C (which indicates the ratio of apolipoprotein B:apolipoprotein A1) is twice as informative [Lewington et al., 2007] of individual CVD risk than TC or LDL-C, and differences in this ratio within and between populations are predominantly due to lifestyle factors (diet, physical activity, obesity, alcohol use). Thus, the ratio of TC:HDL-C is probably the most robust lipid metric to estimate lifestyle factor-related CVD risk.

Variation across population groups in plasma lipids has traditionally been due to differences in TC and LDL-
$\mathrm{C}$, although, with the worldwide obesity pandemic, atherogenic dyslipidaemia (raised TAG, low HDL-C) is increasingly prevalent. The equation developed by Keys has been widely used to predict changes in TC between diets [Keys and Parlin, 1966]:

$$
\Delta \text { serum cholesterol mg/dl }=2.3(\Delta \mathrm{S})-\Delta \mathrm{P}+1.5(\sqrt{ } \Delta \mathrm{C})
$$

$\Delta \mathrm{S}$ is the difference in \% energy from SFA excluding stearic acid, $\Delta \mathrm{P}$ is the difference in \% energy from PUFA and $\Delta \mathrm{C}$ is the difference in cholesterol content in $\mathrm{mg} / 1,000$ $\mathrm{kcal}$; to convert to $\mathrm{mmol} / \mathrm{l}$ divide by 38.5 .

Table 1 summarizes the influence of different individual fatty acids on the different lipoprotein fractions that have been evaluated in a numerous controlled studies. Meta-analyses of these studies provide convincing evidence that SFA (C12-16) elevate TC, LDL-C and HDL-C compared with carbohydrates. The replacement of myristic (C14:0) and palmitic (C16:0) acids with carbohydrates results in little net change in the TC:HDL-C ratio. Lauric acid (C12:0) raises LDL-C and HDL-C and decreases the TC:HDL-C ratio by -0.037 for each $1 \%$ energy when it replaces carbohydrates [Mensink et al., 2003]. However, it is to be noted that coconut oil, which is the major dietary source of lauric acid, has a less favourable effect on the TC/HDL-C ratio than palm oil, which is rich in palmitic and oleic acid [Ng et al., 1992; Sundram et al., 1994]. Stearic acid (C18:0) does not have any significant effects on TC or LDL-C or the TC:HDL-C ratio compared with carbohydrates. There is possible evidence to suggest that the TC- and LDL-C-raising effects of palmitic acid are lower for vegetable than animal sources, because it is present predominantly in the sn- 1 and $s n-3$ 
position as opposed to the sn-2 position as in animal fats such as lard [Choudhury et al., 1995; Zhang et al., 1997]. Animal fats also contain dietary cholesterol, and while the influence of dietary cholesterol on plasma TC and LDL-C is often dismissed as trivial, Keys and Parlin [1966] estimated that each $100 \mathrm{mg}$ of dietary cholesterol raised TC by $4 \mathrm{mg} / \mathrm{dl}(0.11 \mathrm{mmol} / \mathrm{l})$. A more recent metaanalysis [Weggemans et al., 2001] concluded that for most individuals over the range of practical intake $(0-400 \mathrm{mg} /$ day), each $100 \mathrm{mg}$ leads to increases in TC by 0.056 $\mathrm{mmol} / \mathrm{l}$ (95\% CI: $0.046-0.065 \mathrm{mmol} / \mathrm{l})$ and HDL-C by $0.008 \mathrm{mmol} / \mathrm{l}$ (95\% CI: $0.005-0.010 \mathrm{mmol} / \mathrm{l})$, increasing the TC:HDL-C ratio by 0.02 . However, some individuals, especially those carrying the apolipoprotein E $\varepsilon 4$ allele, are more sensitive to dietary cholesterol and a $10 \%$ increase in TC can result from an additional $300 \mathrm{mg}$ cholesterol/day [Sarkkinen et al., 1998]. There is also some evidence to suggest an interaction between SFA and TFA intake with dietary cholesterol. Plant sterols and stanols block the absorption of dietary and biliary cholesterol, and lower TC, LDL-C and the TC:HDL-C ratio independent of changes in fatty acid composition, but these effects are only significant following the consumption of food products fortified with plant sterols/stanols [Law, 2000].

Compared with carbohydrates, the major MUFA (oleic acid; C18:1n-9) has a neutral effect on plasma LDL-C, and PUFA (mainly linoleic acid; C18:2n-6) have a slight lowering effect on TC and LDL-C. Compared with oleic acid, SFA increase HDL-C, and intakes of linoleic acid above $12 \%$ energy lower HDL-C. There is convincing evidence that the replacement of SFA with unhydrogenated vegetable oils rich in cis unsaturated fatty acids results in a reduction in the TC:HDL-C ratio by approximately 0.029 , and by 0.035 for each $1 \%$ energy of SFA replaced with oleic acid and linoleic acid, respectively [Mensink et al., 2003]. This meta-analysis indicated that replacement of saturated or $\mathrm{C} 18$ cis unsaturated fats with carbohydrate increases fasting TAG, at least in the short term.

Compared with carbohydrate, TFA raise LDL-C, but have a similar effect as carbohydrate on HDL-C [Mensink and Katan, 1990; Nestel et al., 1992; Judd et al., 1994; Almendingen et al., 1995; Aro et al., 1997; Lichtenstein et al., 1999; Sanders et al., 2003b; Mozaffarian and Clarke, 2009]. Replacing $1 \%$ energy TFA by carbohydrate, oleic acid or linoleic acid lowers the TC:HDL-C ratio by 0.022 , 0.054 and 0.067 , respectively. Most studies have investigated the effect of partially hydrogenated vegetable oil, although 3 studies used chemically isomerized high oleic sunflower oil as a source of TFA [Mensink and Katan, 1990; Aro et al., 1997; Sanders et al., 2003b]. A recent study compared the effects of 5\% energy of TFA (11-12 $\mathrm{g}$ /day) from natural sources compared to those derived from industrial sources in men and women. This study reported that only industrially produced TFA lowered HDL-C [Chardigny et al., 2008], but the natural sources raised LDL-C compared with the industrial sources. Subgroup analysis suggested the effect was more marked in women. A second study [Motard-Bélanger et al., 2008] compared low (4.2 g/day) and high intakes (10.2 g/day) of ruminant TFA with industrial TFA in 38 men. This study showed a significant increase in TC and LDL-C, with the high intake of trans from either natural or industrial sources, and in the TC:HDL-C ratio. The reduction in HDL-C following an increased intake of TFA is a consequence of a fall in HDL2 cholesterol concentrations [Judd et al., 1994; Sanders et al., 2003b; Motard-Bélanger et al., 2008], which is not dissimilar to the effect observed when carbohydrate replaces fat. However, the LDL-C:HDL-C ratio is higher following an increased intake of TFA compared with the diets high in carbohydrate. Some [Nestel et al., 1992; Judd et al., 1994; Almendingen et al., 1995; Aro et al., 1997; Motard-Bélanger et al., 2008] have reported that TFA increase $\mathrm{Lp}(\mathrm{a})$ concentration, but this difference could equally be explained by differences in fatty acid chain length of the predominant fatty acids in the diet [Sanders et al., 1997]. Many of the comparisons have used palmitic-, myristic- and lauric-rich fats to replace C18:1 trans, and this might explain why palm oil resulted in a lower $\mathrm{Lp}$ (a) concentration compared with partially hydrogenated soybean oil [Sundram et al., 1997]. Sanders et al. [2003b], in a head-to-head comparison of C18:1 provided either as cis or trans, found no difference in $\mathrm{Lp}$ (a) concentrations; a result echoed in a recent comparison [Chardigny et al., 2008] of industrially produced and naturally occurring TFA.

Most studies that have demonstrated effects of TFA on serum lipids have used very high intakes, and the impact of lowering intakes from 2 to $1 \%$ of the energy would have a smaller impact on the TC:HDL-C ratio than decreasing the intake of SFA by $5 \%$ energy. For example, replacing $1 \%$ energy TFA with $1 \%$ energy from oleate would lower TC by $0.036 \mathrm{mmol} / \mathrm{l}$ and increase HDL-C by $0.008 \mathrm{mmol} / \mathrm{l}$, whereas replacing 5\% energy from SFA (3.3\% from C16:0, $1.2 \%$ from C18:0, $0.3 \%$ from C14:0) with oblate would lower TC by $0.2 \mathrm{mmol} / \mathrm{l}$ without changing HDL-C.

Interesterification is a technique increasingly being used by the food industry to generate fats with defined physical properties as an alternative to the partial hydrogenation of fats. However, the health effects of these changes have received little attention. Zock et al. [1995] 
noted a greater increase in LDL-C of $0.08 \mathrm{mmol} / \mathrm{l}$ when palmitate was in the sn-2 position in men, but not in women. Sundram et al. [2007], in a cross-over study of 30 Malaysian subjects (20 female and 10 male), reported that palm olein had a more favourable effect on the TC: HDL-C ratio than partially hydrogenated soybean oil or an interesterified fat made from fully hydrogenated soybean oil and unhydrogenated soybean oil, which was rich in stearic acid. Mensink [2008] compared products made from a high-palmitic-acid trans-free semi-liquid fat or a high-oleic-acid low-trans high-stearic-acid semiliquid fat and found that the palmitic acid-rich diet raised LDL-C and HDL-C by 0.34 and $0.06 \mathrm{mmol} / \mathrm{l}$, respectively, compared with the high-oleic interesterified blend. Berry et al. [2007a] compared native shea butter, rich in stearic acid and naturally present exclusively in the sn-1 and sn-3 positions, with randomized shea butter in 19 male subjects before and after a low-stearate diet and found no difference in TC or HDL-C between randomized and native shea butter or with the low-stearate runin period. The evidence to date thus suggests that interesterified fats where stearic acid is present in the sn-2 position probably have a neutral effect on blood lipids [Berry, 2009]. However, further research is urgently needed on whether the commercial interesterification of vegetable fats (including fully hydrogenated fats), which is widely carried out in the food industry, influences plasma LDL-C and HDL-C and other indices of CVD risk.

Long-chain n-3 PUFA [n-3 LCP: mainly eicosapentaenoic acid (C20:5n-3; EPA) and docosahexaenoic acid (C22:6n-3; DHA)] generally supplied in the diet by oily fish have no effect on TC [Bays, 2006], but lower plasma TAG and VLDL cholesterol and raise LDL-C concentrations [Theobald et al., 2004; Caslake et al., 2008] in amounts exceeding $0.7 \mathrm{~g} /$ day $(\sim 0.3 \%$ energy). Dietary supplements, usually providing in excess of $3 \mathrm{~g} n-3 \mathrm{LCP} /$ day, lower plasma TAG on average by $27 \%$, but have variable effects on LDL-C and HDL-C depending on the dose, type of fatty acid and lipoprotein phenotype: on average they increase both LDL-C (6\%) and HDL-C (1.4\%) concentrations, but also LDL and HDL particle size [Minihane et al., 2000; Griffin et al., 2006; Kelley et al., 2007]. DHA from algal sources in the range of 0.7-1.5 $\mathrm{g}$ /day raises TC and LDL-C between 6 and 12\%, but has little influence on the TC:HDL-C ratio [Theobald et al., 2004; Geppert et al., 2006; Sanders et al., 2006a]. Linolenic acid does not share the effects shown by n-3 LCP and does not influence plasma lipid concentrations within the range of intakes likely to be encountered in human diets [Balk et al., 2006].

Metabolic Effects of Fat and Fatty Acid Intake
There is convincing evidence [Whitlock et al., 2009] that individuals who maintain a healthy weight are less likely to develop a raised TC:HDL ratio. Furthermore, weight loss in overweight or obese subjects results in improvements in circulating lipid concentrations, including raising $\mathrm{HDL}-\mathrm{C}$, lowering TAG and TC, and improving the TC:HDL-C ratio [Yu-Poth et al., 1999].

Despite the global increase in obesity, TC and LDL-C have fallen in several economically developed countries [Vartiainen et al., 2000; Evans et al., 2001; Carroll et al., 2005] where the fat supply has changed from predominantly animal fats (dairy fats, lard, lamb and beef fat), rich in SFA, to vegetable oils rich in cis unsaturated fatty acids [Vartiainen et al., 2000]. In contrast, there is evidence to suggest that TC and LDL-C are increasing in some emerging economies such as China [Critchley et al., 2004], and that this is accompanied by an increase in total and saturated fat from both animal and vegetable sources. However, in many developing countries, it is not possible to dissociate the effect on TC of an increase in BMI from lean to moderately elevated BMI [Whitlock et al., 2009].

\section{Postprandial Lipid Metabolism}

While most attention has focused on fasting lipid and lipoprotein concentrations, for most of the time humans are in the postprandial state, and variations in the nonfasting lipid concentrations may also influence the atherogenic process. Elevated postprandial lipid concentrations, resulting from meals typically containing 30-50 g fat, and persistent elevation of postprandial plasma TAG are associated with progression of atherosclerosis and increased risk of thrombosis. Impaired postprandial lipaemia is associated with obesity, insulin resistance and type 2 diabetes. Compared with meals low in fat and high in carbohydrate, meals high in long-chain fatty acids (C1418) result in substantial lipaemia. Short- and mediumchain fatty acids (C2-C12) do not result in substantial lipaemia [Oakley et al., 1998; Sanders et al., 2000, 2001]. Stearic-rich fats result in variable effects on postprandial lipaemia according to the physical properties of the fat [Sanders et al., 2000, 2001, 2003a; Tholstrup et al., 2001; Berry et al., 2007a]. Most stearic-rich TAG result in decreased postprandial lipaemia compared to oleic acid-rich TAG, and this appears to be a consequence of the high melting point of the TAG delaying its absorption.

Trans isomeric fatty acids have similar effects compared to cis isomeric fatty acids [Sanders et al., 2000, 
2003b; Tholstrup et al., 2001]. Intakes in excess of $1.5 \mathrm{~g}$ n-3 LCP result in decreased postprandial lipaemia, both acutely and chronically [Harris and Muzio, 1993; Zampelas et al., 1994; Griffin et al., 2006], probably by way of their effects on reducing VLDL synthesis, which in turn reduces competition for clearance of chylomicron remnants. There is consistent evidence that prolonged elevations of plasma TAG concentrations result in an increased proportion of small dense LDL particles that are associated with increased progression of atherosclerosis and increased risk of coronary heart disease [Kwiterovich, 2002]. Diets containing a higher proportion of carbohydrate in place of fat result in an increase in plasma TAG concentrations in the fasting state, but a lower plasma TAG concentration in the postprandial state. However, there is no consistent evidence from randomized controlled trials to indicate that diets with a reduced proportion of energy from fat result in an increased proportion of small dense LDL. There is, however, evidence to show that weight loss, leading to a reduction in adipose tissue, decreases the proportion of small dense LDL [Siri-Tarino et al., 2009].

\section{Insulin Sensitivity}

Regular physical activity and weight loss in overweight or obese subjects improve insulin sensitivity [Costacou and Mayer-Davis, 2003; Roumen et al., 2008]. Animal studies indicate that diets rich in SFA impair insulin sensitivity, and that $\mathrm{n}-3 \mathrm{LCP}$ improve insulin sensitivity. The euglycaemic insulin clamp technique is regarded as the gold standard for the measurement of insulin sensitivity. However, few studies have investigated the effect of fat modification using this technique, and where it has been employed, the sample size is insufficient to come to any clear conclusion. Most of the larger studies have assessed insulin sensitivity using the intravenous glucose tolerance test. While this technique measures tissue sensitivity to insulin, it does not fully measure the response to diet, which is also influenced by incretins secreted in the gut in response to food.

There is limited evidence that replacing SFA from animal sources with MUFA from plant sources improves insulin sensitivity and glycaemic control in type 2 diabetes [Garg, 1998]. However, randomized controlled trials [Vessby et al., 2001; Griffin et al., 2006; Tardy et al., 2009] have generally failed to show any consistent effect of changing either the level of fat or the type of fat on insulin sensitivity when changes in weight or physical activ- ity are taken into account. Where a reduction in the dietary intake of fat is accompanied by a reduction in energy intake and weight loss, an improvement in insulin sensitivity is likely.

\section{Indices of Oxidative Stress}

There is convincing mechanistic evidence [Griendling and FitzGerald, 2003] to implicate lipoprotein oxidation in the pathogenesis of atherosclerosis, but the consequences of altering lipoprotein oxidation [Reaven et al., 1991; Finnegan et al., 2003; Caslake et al., 2008] in human studies through increasing/decreasing the proportion of dietary PUFA are not well established. A number of biomarkers of oxidative damage are available, but none are strongly predictive of risk of CVD, and there is no convincing evidence to demonstrate that modifying the composition of dietary fat has a significant impact on the process of lipoprotein oxidation in vivo. Furthermore, randomized controlled trials of antioxidant compounds have failed to demonstrate any benefit on cardiovascular risk [Bjelakovic et al., 2007].

\section{Inflammatory Markers}

Chronic inflammation results in the elevation of acute-phase proteins, including fibrinogen and C-reactive protein, and is believed to be mediated by elevated production of cytokines, particularly IL-6. Chronic inflammation, as indicated by mild elevations of C-reactive protein, increases the risk of CVD - especially if the TC: HDL-C ratio is high [Ridker, 2001]. Obesity may directly contribute to the increased production of IL- 6 from adipose tissue. Postprandial lipaemia may also stimulate the production of inflammatory cytokines. One mechanism suggested is that postprandial lipaemia may increase the absorption of endotoxin from the gut [Erridge et al., 2007]. Evidence has also been presented [Byrne et al., 1998; Grainger et al., 2000] that TAG-rich lipoproteins sequester the active form of the atheroprotective cytokine TGF $\beta 1$. High intakes of $n-3$ LCP ( $>3$ g/day) in the form of dietary supplements [Meydani, 2000; Vedin et al., 2008] decrease cytokine production and probably decrease inflammatory markers, but randomized controlled trials, using lower intakes as may habitually be consumed in usual diets, have failed to demonstrate any clear effects on cytokines, adhesion molecules or C-reactive protein [Blok et al., 1997; Balk et al., 2006; Theobald 
et al., 2007]. There is possible evidence that TFA increase systemic inflammation [Baer et al., 2004], but not all studies have consistently shown such effects [MotardBélanger et al., 2008].

\section{Procoagulant and Fibrinolytic Activity}

Elevated procoagulant FVII and fibrinogen and decreased indices of fibrinolytic activity (as assessed by measures of clot lysis time or elevated plasminogen activator inhibitor PAI-1 activity) are associated with an increased risk of atherothrombosis [Meade et al., 1993; Heinrich et al., 1994; Folsom et al., 2001]. Hyperlipidaemia is associated with elevated FVII and fibrinogen, and insulin resistance syndrome is associated with elevated PAI-1. There is possible evidence that n-3 LCP, provided as dietary supplements, increase FVIIc [Sanders et al., 2006a], but this effect was not evident with an increased intake from oily fish [Sanders et al., 2006b]. There is convincing evidence that meals high in fat (usually $50 \mathrm{~g}$ fat) compared to meals high in carbohydrate and low in fat $(<15 \mathrm{~g}$ fat) acutely increase the concentration of FVIIa [Oakley et al., 1998; Sanders et al., 1999, 2000, 2001, 2003b, 2006b; Tholstrup et al., 2003; Sanders and Berry, 2005]. There is probable evidence that the increase in FVIIa is greater following meals rich in MUFA (oleic acid) than for some sources of SFA [Sanders et al., 2000, 2006b; Tholstrup et al., 2003; Sanders and Berry, 2005; Berry et al., 2007a, b]. There is insufficient evidence to demonstrate chronic effects of different types of fatty acids on fibrinogen or fibrinolytic activity [Miller, 2005; Sanders et al., 2006b], but fibrinolytic activity improves with intensive lifestyle intervention (weight reduction and increased physical activity) [Hamalainen et al., 2005].

\section{Blood Pressure and Arterial Stiffness}

Both systolic and diastolic blood pressure increase with age in economically developed communities and show a continuous association with risk of CVD without a threshold [Lewington and Clarke, 2005]. Elevated blood pressure is a self-amplifying condition and is strongly associated with BMI. There is also a strong association between the development of hypertension and hyperlipidaemia. There is convincing evidence that weight loss results in a fall in blood pressure [Neter et al., 2003]. A 5-kg loss in weight results in systolic/diastolic blood pressure falls of 4.4/3.6 mm Hg. In this respect, a reduction in total fat

Metabolic Effects of Fat and Fatty Acid Intake intake that results in lower energy intake and weight loss will lower blood pressure. However, there is no clear evidence to indicate the superiority of low-calorie diets that contain a higher proportion of fat than carbohydrate.

There is convincing evidence for a blood pressurelowering effect of replacing SFA with MUFA as part of a healthy lifestyle diet [Appel et al., 2003, 2005] with an increased proportion of fruit and vegetables, wholegrains and reduced salt intake. There is insufficient evidence that replacement of saturated fats with MUFA alone has a significant effect on blood pressure [Shah et al., 2007]. There is possible evidence from cross-sectional studies that linoleic acid may contribute to the prevention of raised blood pressure [Miura et al., 2008]. High intakes (>2 g/day) of n-3 LCP convincingly lower blood pressure [Geleijnse et al., 2002], and there is possible evidence that habitual intakes at lower levels have the same effect [Ueshima et al., 2007]. Over the age of 60 years, systolic blood pressure increases more than diastolic blood pressure, and this is likely in part to be a consequence of arterial stiffening. Arterial stiffness is emerging as a strong predictor of CVD risk in the elderly [Terai et al., 2008; Anderson et al., 2009]. There is possible evidence that n-3 LCP may decrease arterial stiffening [Hamazaki et al., 1988; Yamada et al., 2000; Tomiyama et al., 2005; Terai et al., 2008].

\section{Endothelial Function}

Impaired endothelial function plays a central role in atherogenesis and also increases the risk of arterial thrombosis. The capacity of the vascular endothelium to synthesize nitric oxide (NO) and NO bioavailability are important determinants of normal endothelial function. NO appears to have both anti-thrombotic and anti-atherosclerotic properties. The capacity of the endothelium to synthesise NO can be assessed in vivo by measuring flow-mediated dilatation of the brachial artery. Impaired flow-mediated dilatation is associated with the risk of atherosclerotic disease [Yeboah et al., 2007]. Hyperlipidaemia and hyperglycaemia are 2 factors known to impair endothelial function. Meals high in long-chain fatty acids, which induce substantial lipaemia compared with meals low in fat but high in carbohydrate, result in an impairment of endothelial function in the postprandial period in healthy subjects [Vogel et al. 1997, 2000; Ong et al., 1999; Bae et al., 2001; Cortés et al., 2006]. There is possible evidence that $\mathrm{n}-3$ LCP may improve [Goodfellow et al., 2000; Leeson et al., 2002; Engler et al., 2004] 
Table 2. Summary of strength of evidence for metabolic risk factors excluding fasting lipids

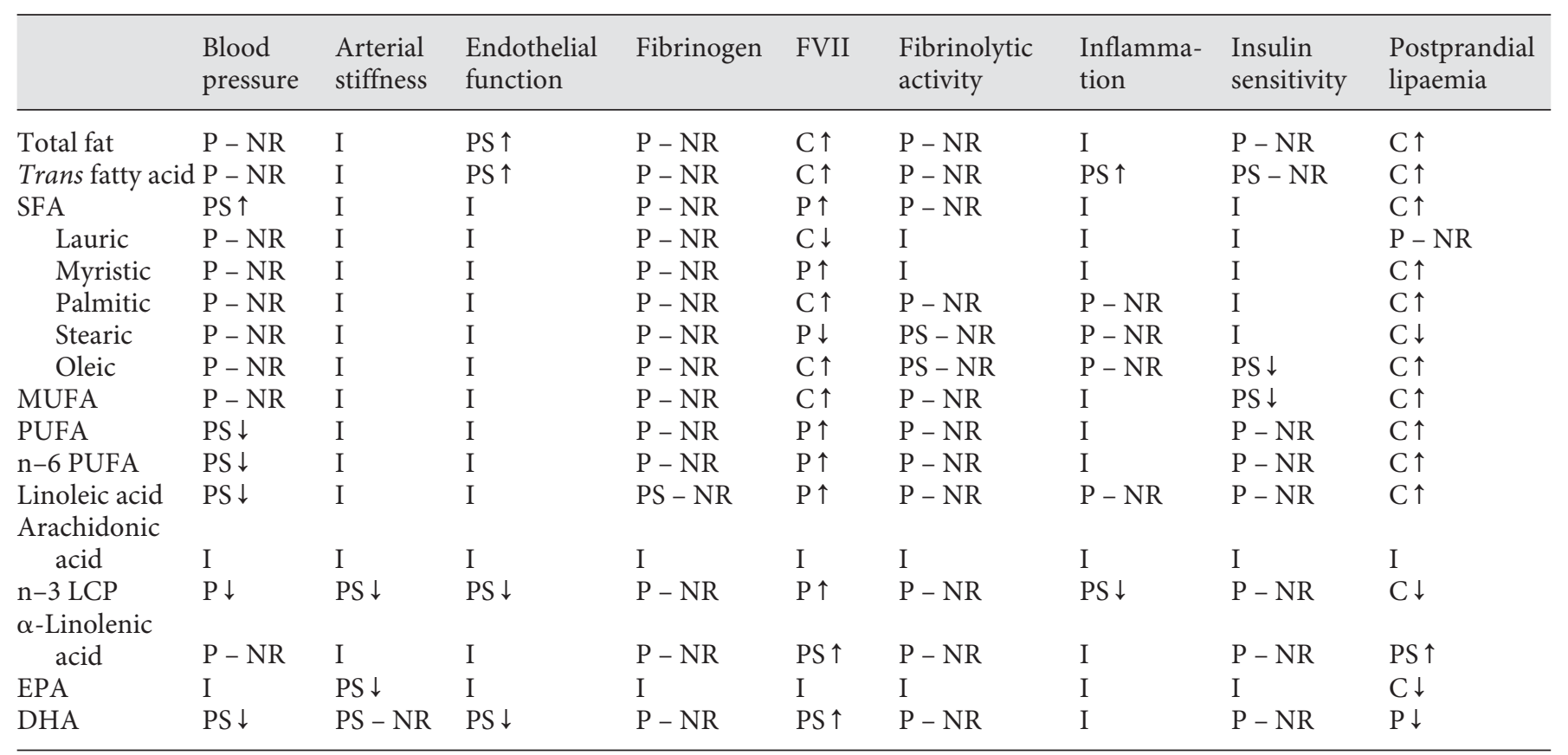

$\mathrm{C}=$ Convincing; $\mathrm{P}=$ probable; $\mathrm{PS}=$ possible; $\mathrm{I}=$ Insufficient $\uparrow$ increased risk; $\downarrow$ decreased risk; NR = no relationship.

and TFA [de Roos et al., 2001] may impair endothelial function. Early chronic feeding studies have been subject to operator-dependent variability [Hall, 2009]. Consequently, there is insufficient evidence to conclude that there are any other differences between MUFA, PUFA and SFA.

\section{Dietary Interactions with Genotype}

Several gene polymorphisms for lipid and haemostatic risk factors have been identified that may have interactions with dietary fat intake. Subjects who carry the $\varepsilon 4$ allele for apolipoprotein have higher TC and LDL-C concentrations compared to those carrying the common $\varepsilon 3$ allele. These $\varepsilon 4$ carriers appear to show greater absolute (but not proportionately different) falls in TC and LDL-C compared with $\varepsilon 3$ carriers when they decrease their intakes of SFA and cholesterol [Lefevre et al., 1997]. However, the LDL-C-raising effect of n-3 LCP does not differ between $\varepsilon 4$ and $\varepsilon 3$ carriers [Theobald et al., 2004; Caslake et al., 2008]. Cross-sectional data do not suggest that the apolipoprotein E genotype is an important determinant in the LDL-C response to SFA [Wu et al., 2007]. Subjects who are homozygous for the $\varepsilon 2$ allele do not show an in- crease in serum cholesterol in response to dietary cholesterol, but this genotype is associated with an increased prevalence of WHO type II hyperlipoproteinaemia, which responds to a low-fat diet.

About 1:500 people carry mutations for the LDL receptor. These individuals have higher TC and LDL-C and a 25-fold increased risk of developing premature CVD. Plasma TC and LDL-C concentrations in individuals who carry this mutation are relatively unresponsive to changes in the level or type of dietary fat [Poustie and Rutherford, 2001].

\section{Conclusions}

There is convincing evidence that the major determinants of differences in metabolic risk factors within and across populations are due to behavioural and lifestyle factors (diet, physical activity, obesity, smoking, alcohol use) rather than genetic differences. Decreasing the intake of SFA C12-16 and their replacement with oleic and linoleic acids lowers TC and LDL-C without lowering HDL-C and has a more favourable effect on the TC: HDL-C ratio than replacement with carbohydrate, particularly in populations where a high proportion of the 
population is overweight or obese. The intake of SFA has fallen close to $10 \%$ in several economically developed countries because the fat supply has changed from predominantly animal fats (dairy fats, lard, lamb and beef fat), rich in SFA, to vegetable oils rich in cis unsaturated fatty acids. Consequently, in those countries, the capacity to decrease SFA much further is limited without major changes in dietary patterns, and is only likely to result in modest reductions in TC and LDL-C. TFA have adverse effects on the TC:HDL-C ratio. Therefore, replacing TFA with cis unsaturated fatty acids is preferred, but some food applications require high-melting-point fats. Stearic acid appears to have no effect on the LDL-C or TC: HDL-C ratio. Thus, this need could be met by the use of fully hydrogenated vegetable oils interesterified with unhydrogenated fat, which results in the production of TAG with a significant proportion of stearic acid in the sn-2 position, or by blending with fats that have high melting points, such as palm oil. Further research on the health effects of these approaches is required.

The effects of total fat and the various fatty acids on other CVD risk factors are shown in table 2. There is possible evidence to suggest that long-chain n-3 fatty acids may influence arterial stiffening and have favourable effects on endothelial function, but this requires further research. Dietary fat intake has no clear effect on blood pressure, inflammation, fibrinolysis or insulin sensitivity, whereas these risk factors are strongly influenced by obesity. Meals high in fat, however, cause postprandial lipaemia and may promote atherosclerosis as well has having a potentially adverse influence on the risk of thrombotic events by way of effects on procoagulant activity and endothelial function. There is a need for further research in this area as the modulation of risk of thrombosis may be of greater importance in older populations who have established atherosclerosis and are most at risk of cardiovascular events.

\section{Disclosure Statement}

T.A.B.S. has acted as a consultant to Seven Seas, he is a member of the Scientific Advisory Committee for the Global Dairy Platform, he is a member of the external scientific review committee of the Malaysian Palm Oil Board, he chairs Cadbury's Global Nutrition Advisory Panel. His research group has received oils and fats from Unilever, Archer Daniel Mills and Croda gratis for research. He has received payments from several industrial companies for attending workshops and giving lectures. He receives research funding from the UK Food Standards Agency.

\section{References}

Almendingen K, Jordal O, Kierulf P, Sandstad B, Pedersen JI: Effects of partially hydrogenated fish oil, partially hydrogenated soybean oil, and butter on serum lipoproteins and Lp(a) in men. J Lipid Res 1995;36:13701384 .

-Anderson SG, Sanders TA, Cruickshank JK: Plasma fatty acid composition as a predictor of arterial stiffness and mortality. Hypertension 2009;53:839-845.

- Appel LJ, Champagne CM, Harsha DW, et al: Effects of comprehensive lifestyle modification on blood pressure control: main results of the PREMIER clinical trial. JAMA 2003;289: 2083-2093.

Appel LJ, Sacks FM, Carey VJ, et al: Effects of protein, monounsaturated fat, and carbohydrate intake on blood pressure and serum lipids: results of the OmniHeart randomized trial. JAMA 2005;294:2455-2464.

-Aro A, Jauhiainen M, Partanen R, Salminen I, Mutanen M: Stearic acid, trans fatty acids, and dairy fat: effects on serum and lipoprotein lipids, apolipoproteins, lipoprotein(a), and lipid transfer proteins in healthy subjects. Am J Clin Nutr 1997;65:1419-1426.
Bae JH, Bassenge E, Kim KB, et al: Postprandial hypertriglyceridemia impairs endothelial function by enhanced oxidant stress. Atherosclerosis 2001;155:517-523.

Baer DJ, Judd JT, Clevidence BA, Tracy RP: Dietary fatty acids affect plasma markers of inflammation in healthy men fed controlled diets: a randomized crossover study. Am J Clin Nutr 2004;79:969-973.

Balk EM, Lichtenstein AH, Chung M, Kupelnick B, Chew P, Lau J: Effects of omega-3 fatty acids on serum markers of cardiovascular disease risk: a systematic review. Atherosclerosis 2006;189:19-30.

Bays H: Clinical overview of Omacor: a concentrated formulation of omega-3 polyunsaturated fatty acids. Am J Cardiol 2006;98:71i$76 \mathrm{i}$.

Berry SE: Triacylglycerol structure and interesterification of palmitic and stearic acidrich fats: an overview and implications for cardiovascular disease. Nutr Res Rev 2009; 22:3-17.

Berry SE, Miller GJ, Sanders TA: The solid fat content of stearic acid-rich fats determines their postprandial effects. Am J Clin Nutr 2007a;85:1486-1494.
Berry SE, Woodward R, Yeoh C, Miller GJ, Sanders TA: Effect of interesterification of palmitic acid-rich triacylglycerol on postprandial lipid and factor VII response. Lipids 2007b;42:315-323.

Bjelakovic G, Nikolova D, Gluud LL, Simonetti RG, Gluud C: Mortality in randomized trials of antioxidant supplements for primary and secondary prevention: systematic review and meta-analysis. JAMA 2007;297:842857.

Blok WL, Deslypere JP, Demacker PN, et al: Proand anti-inflammatory cy tokines in healthy volunteers fed various doses of fish oil for 1 year. Eur J Clin Invest 1997;27:1003-1008.

- Brown JM, Shelness GS, Rudel LL: Monounsaturated fatty acids and atherosclerosis: opposing views from epidemiology and experimental animal models. Curr Atheroscler Rep 2007;9:494-500.

Byrne CD, Wareham NJ, Martensz ND, Humphries SE, Metcalfe JC, Grainger DJ: Increased PAI activity and PAI-1 antigen occurring with an oral fat load: associations with PAI-1 genotype and plasma active TGFbeta levels. Atherosclerosis 1998;140:45-53. 
Carroll MD, Lacher DA, Sorlie PD, et al: Trends in serum lipids and lipoproteins of adults, 1960-2002. JAMA 2005;294:1773-1781.

-Caslake MJ, Miles EA, Kofler BM, et al: Effect of sex and genotype on cardiovascular biomarker response to fish oils: the FINGEN Study. Am J Clin Nutr 2008;88:618-629.

-Chardigny JM, Destaillats F, Malpuech-Brugère C, et al: Do trans fatty acids from industrially produced sources and from natural sources have the same effect on cardiovascular disease risk factors in healthy subjects? Results of the trans Fatty Acids Collaboration (TRANSFACT) study. Am J Clin Nutr 2008;87:558-566.

Choudhury N, Tan L, Truswell AS: Comparison of palmolein and olive oil: effects on plasma lipids and vitamin $\mathrm{E}$ in young adults. Am J Clin Nutr 1995;61:1043-1051.

Cortés B, Núñez I, Cofán M, et al: Acute effects of high-fat meals enriched with walnuts or olive oil on postprandial endothelial function. J Am Coll Cardiol 2006;48:1666-1671.

Costacou T, Mayer-Davis EJ: Nutrition and prevention of type 2 diabetes. Annu Rev Nutr 2003;23:147-170.

C Critchley J, Liu J, Zhao D, Wei W, Capewell S: Explaining the increase in coronary heart disease mortality in Beijing between 1984 and 1999. Circulation 2004;110:1236-1244.

-de Roos NM, Bots ML, Katan MB: Replacement of dietary saturated fatty acids by trans fatty acids lowers serum HDL cholesterol and impairs endothelial function in healthy men and women. Arterioscler Thromb Vasc Biol 2001;21:1233-1237.

EFSA: Opinion of the Scientific Panel on Dietetic Products, Nutrition and Allergies on a request from the Commission related to the presence of trans fatty acids in foods and the effect on human health of the consumption of trans fatty acids. EFSA J 2004;81:1-49.

-Engler MM, Engler MB, Malloy M, et al: Docosahexaenoic acid restores endothelial function in children with hyperlipidemia: results from the EARLY study. Int J Clin Pharmacol Ther 2004;42:672-679.

-Erridge C, Attina T, Spickett CM, Webb DJ: A high-fat meal induces low-grade endotoxemia: evidence of a novel mechanism of postprandial inflammation. Am J Clin Nutr 2007;86:1286-1292.

- Evans A, Tolonen H, Hense HW, Ferrario M, Sans S, Kuulasmaa K: Trends in coronary risk factors in the WHO MONICA project. Int J Epidemiol 2001;30(suppl 1):S35-S40.

Expert Panel on Detection, Evaluation, and Treatment of High Blood Cholesterol in Adults: Executive Summary of The Third Report of The National Cholesterol Education Program (NCEP) Expert Panel on Detection, Evaluation, And Treatment of High Blood Cholesterol In Adults (Adult Treatment Panel III). JAMA 2001;285:24862497.
Finnegan YE, Minihane AM, Leigh-Firbank EC, et al: Plant- and marine-derived $n-3$ polyunsaturated fatty acids have differential effects on fasting and postprandial blood lipid concentrations and on the susceptibility of LDL to oxidative modification in moderately hyperlipidemic subjects. Am J Clin Nutr 2003; 77:783-795.

Folsom AR, Aleksic N, Park E, Salomaa V, Juneja H, Wu KK: Prospective study of fibrinolytic factors and incident coronary heart disease: the Atherosclerosis Risk in Communities (ARIC) Study. Arterioscler Thromb Vasc Biol 2001;21:611-617.

- Garg A: High-monounsaturated-fat diets for patients with diabetes mellitus: a meta-analysis. Am J Clin Nutr 1998;67:577S-582S.

-Geleijnse JM, Giltay EJ, Grobbee DE, Donders AR, Kok FJ: Blood pressure response to fish oil supplementation: metaregression analysis of randomized trials. J Hypertens 2002; 20:1493-1499.

- Geppert J, Kraft V, Demmelmair H, Koletzko B: Microalgal docosahexaenoic acid decreases plasma triacylglycerol in normolipidaemic vegetarians: a randomised trial. $\mathrm{Br} \mathrm{J}$ Nutr 2006;95:779-786.

Goodfellow J, Bellamy MF, Ramsey MW, Jones CJ, Lewis MJ: Dietary supplementation with marine omega-3 fatty acids improve systemic large artery endothelial function in subjects with hypercholesterolemia. J Am Coll Cardiol 2000;35:265-270.

Grainger DJ, Mosedale DE, Metcalfe JC, Bottinger EP: Dietary fat and reduced levels of TGFbeta1 act synergistically to promote activation of the vascular endothelium and formation of lipid lesions. J Cell Sci 2000; 113(part 13):2355-2361.

Griendling KK, FitzGerald GA: Oxidative stress and cardiovascular injury. II. Animal and human studies. Circulation 2003;108:20342040.

Griffin MD, Sanders TA, Davies IG, et al: Effects of altering the ratio of dietary n- 6 to $n-3$ fatty acids on insulin sensitivity, lipoprotein size, and postprandial lipemia in men and postmenopausal women aged 45-70 years: the OPTILIP Study. Am J Clin Nutr 2006;84: 1290-1298.

Hall WL: Dietary saturated and unsaturated fats as determinants of blood pressure and vascular function. Nutr Res Rev 2009;22:1838.

Hamalainen H, Ronnemaa T, Virtanen A, et al: Improved fibrinolysis by an intensive lifestyle intervention in subjects with impaired glucose tolerance. The Finnish Diabetes Prevention Study. Diabetologia 2005;48:22482253.

Hamazaki T, Urakaze M, Sawazaki S, Yamazaki K, Taki H, Yano S: Comparison of pulse wave velocity of the aorta between inhabitants of fishing and farming villages in Japan. Atherosclerosis 1988;73:157-160.
Harris WS, Muzio F: Fish oil reduces postprandial triglyceride concentrations without accelerating lipid-emulsion removal rates. Am J Clin Nutr 1993;58:68-74.

-Heinrich J, Balleisen L, Schulte H, Assmann G, van de Loo J: Fibrinogen and factor VII in the prediction of coronary risk. Results from the PROCAM study in healthy men. Arterioscler Thromb 1994;14:54-59.

Judd JT, Clevidence BA, Muesing RA, Wittes J, Sunkin ME, Podczasy JJ: Dietary trans fatty acids: effects on plasma lipids and lipoproteins of healthy men and women. Am J Clin Nutr 1994;59:861-868.

Kelley DS, Siegel D, Vemuri M, Mackey BE: Docosahexaenoic acid supplementation improves fasting and postprandial lipid profiles in hypertriglyceridemic men. Am J Clin Nutr 2007;86:324-333.

Keys A, Parlin RW: Serum cholesterol response to changes in dietary lipids. Am J Clin Nutr 1966;19:175-181.

Kwiterovich PO Jr: Clinical relevance of the biochemical, metabolic, and genetic factors that influence low-density lipoprotein heterogeneity. Am J Cardiol 2002;90:30i-47i.

Law M: Plant sterol and stanol margarines and health. BMJ 2000;320:861-864.

Leeson CP, Mann A, Kattenhorn M, Deanfield JE, Lucas A, Muller DP: Relationship between circulating $n-3$ fatty acid concentrations and endothelial function in early adulthood. Eur Heart J 2002;23:216-222.

Lefevre M, Ginsberg HN, Kris-Etherton PM, et al: ApoE genotype does not predict lipid response to changes in dietary saturated fatty acids in a heterogeneous normolipidemic population: The DELTA Research Group. Dietary Effects on Lipoproteins and Thrombogenic Activity. Arterioscler Thromb Vasc Biol 1997; 17:2914-2923.

Lewington S, Clarke R: Combined effects of systolic blood pressure and total cholesterol on cardiovascular disease risk. Circulation 2005; 112:3373-3374.

Lewington S, Whitlock G, Clarke R, et al: Blood cholesterol and vascular mortality by age, sex, and blood pressure: a meta-analysis of individual data from 61 prospective studies with 55,000 vascular deaths. Lancet 2007; 370:1829-1839.

- Lichtenstein AH, Ausman LM, Jalbert SM, Schaefer EJ: Effects of different forms of dietary hydrogenated fats on serum lipoprotein cholesterol levels. N Engl J Med 1999; 340:1933-1940.

Meade TW, Ruddock V, Stirling Y, Chakrabarti R, Miller GJ: Fibrinolytic activity, clotting factors, and long-term incidence of ischaemic heart disease in the Northwick Park Heart Study. Lancet 1993;342:1076-1079.

Mensink RP: Effects of products made from a high-palmitic acid, trans-free semiliquid fat or a high-oleic acid, low-trans semiliquid fat on the serum lipoprotein profile and on Creactive protein concentrations in humans. Eur J Clin Nutr 2008;62:617-624. 
Mensink RP, Katan MB: Effect of dietary trans fatty acids on high-density and low-density lipoprotein cholesterol levels in healthy subjects. N Engl J Med 1990;323:439-445.

Mensink RP, Zock PL, Kester AD, Katan MB: Effects of dietary fatty acids and carbohydrates on the ratio of serum total to HDL cholesterol and on serum lipids and apolipoproteins: a meta-analysis of 60 controlled trials. Am J Clin Nutr 2003;77:1146-1155.

Meydani M: Omega-3 fatty acids alter soluble markers of endothelial function in coronary heart disease patients. Nutr Rev 2000;58:5659.

Miller GJ: Dietary fatty acids and the haemostatic system. Atherosclerosis 2005; 179:213227.

Minihane AM, Khan S, Leigh-Firbank EC, et al: ApoE polymorphism and fish oil supplementation in subjects with an atherogenic lipoprotein phenotype. Arterioscler Thromb Vasc Biol 2000;20:1990-1997.

-Miura K, Stamler J, Nakagawa H, et al: Relationship of dietary linoleic acid to blood pressure. The International Study of Macro-Micronutrients and Blood Pressure Study (corrected). Hypertension 2008;52:408-414.

-Motard-Bélanger A, Charest A, Grenier G, et al: Study of the effect of trans fatty acids from ruminants on blood lipids and other risk factors for cardiovascular disease. Am J Clin Nutr 2008;87:593-599.

-Mozaffarian D, Clarke R: Quantitative effects on cardiovascular risk factors and coronary heart disease risk of replacing partially hydrogenated vegetable oils with other fats and oils. Eur J Clin Nutr 2009;63(suppl 2):S22S33.

- Nestel P, Noakes M, Belling B, et al: Plasma lipoprotein lipid and Lp(a) changes with substitution of elaidic acid for oleic acid in the diet. J Lipid Res 1992;33:1029-1036.

- Neter JE, Stam BE, Kok FJ, Grobbee DE, Geleijnse JM: Influence of weight reduction on blood pressure: a meta-analysis of randomized controlled trials. Hypertension 2003;42: 878-884.

Ng TK, Hayes KC, DeWitt GF, et al: Dietary palmitic and oleic acids exert similar effects on serum cholesterol and lipoprotein profiles in normocholesterolemic men and women. J Am Coll Nutr 1992;11:383-390.

-Oakley FR, Sanders TA, Miller GJ: Postprandial effects of an oleic acid-rich oil compared with butter on clotting factor VII and fibrinolysis in healthy men. Am J Clin Nutr 1998; 68:1202-1207.

-Ong PJ, Dean TS, Hayward CS, Della Monica PL, Sanders TA, Collins P: Effect of fat and carbohydrate consumption on endothelial function. Lancet 1999;354:2134.

Poustie VJ, Rutherford P: Dietary treatment for familial hypercholesterolaemia. Cochrane Database Syst Rev 2001;CD001918.
Reaven P, Parthasarathy S, Grasse BJ, et al: Feasibility of using an oleate-rich diet to reduce the susceptibility of low-density lipoprotein to oxidative modification in humans. Am J Clin Nutr 1991;54:701-706.

Ridker PM: High-sensitivity C-reactive protein: potential adjunct for global risk assessment in the primary prevention of cardiovascular disease. Circulation 2001;103:1813-1818.

-Ross R: Atherosclerosis - an inflammatory disease. N Engl J Med 1999;340:115-126.

Roumen C, Corpeleijn E, Feskens EJ, Mensink M, Saris WH, Blaak EE: Impact of 3-year lifestyle intervention on postprandial glucose metabolism: the SLIM study. Diabet Med 2008;25:597-605.

Sanders TA, Berry SE: Influence of stearic acid on postprandial lipemia and hemostatic function. Lipids 2005;40:1221-1227.

-Sanders TA, Berry SE, Miller GJ: Influence of triacylglycerol structure on the postprandial response of factor VII to stearic acid-rich fats. Am J Clin Nutr 2003a;77:777-782.

Sanders TA, de Grassi T, Miller GJ, Humphries SE: Dietary oleic and palmitic acids and postprandial factor VII in middle-aged men heterozygous and homozygous for factor VII R353Q polymorphism. Am J Clin Nutr 1999; 69:220-225.

Sanders TA, de Grassi T, Miller GJ, Morrissey $\mathrm{JH}$ : Influence of fatty acid chain length and cis/trans isomerization on postprandial lipemia and factor VII in healthy subjects (postprandial lipids and factor VII). Atherosclerosis 2000;149:413-420.

-Sanders TA, Gleason K, Griffin B, Miller GJ: Influence of an algal triacylglycerol containing docosahexaenoic acid (22:6n-3) and docosapentaenoic acid (22:5n-6) on cardiovascular risk factors in healthy men and women. Br J Nutr 2006a;95:525-531.

Sanders TA, Lewis F, Slaughter S, et al: Effect of varying the ratio of $n-6$ to $n-3$ fatty acids by increasing the dietary intake of alpha-linolenic acid, eicosapentaenoic and docosahexaenoic acid, or both on fibrinogen and clotting factors VII and XII in persons aged $45-70 \mathrm{y}$ : the OPTILIP study. Am J Clin Nutr 2006b; 84:513-522.

-Sanders TA, Oakley FR, Cooper JA, Miller GJ: Influence of a stearic acid-rich structured triacylglycerol on postprandial lipemia, factor VII concentrations, and fibrinolytic activity in healthy subjects. Am J Clin Nutr 2001;73:715-721.

-Sanders TA, Oakley FR, Crook D, Cooper JA, Miller GJ: High intakes of trans monounsaturated fatty acids taken for 2 weeks do not influence procoagulant and fibrinolytic risk markers for CHD in young healthy men. $\mathrm{Br}$ J Nutr 2003b;89:767-776.

Sanders TA, Oakley FR, Miller GJ, Mitropoulos KA, Crook D, Oliver MF: Influence of n-6 versus $n-3$ polyunsaturated fatty acids in diets low in saturated fatty acids on plasma lipoproteins and hemostatic factors. Arterioscler Thromb Vasc Biol 1997;17:3449-3460.
Sarkkinen E, Korhonen M, Erkkila A, Ebeling T, Uusitupa M: Effect of apolipoprotein E polymorphism on serum lipid response to the separate modification of dietary fat and dietary cholesterol. Am J Clin Nutr 1998;68: 1215-1222.

Seed M, Hoppichler F, Reaveley D, et al: Relation of serum lipoprotein(a) concentration and apolipoprotein(a) phenotype to coronary heart disease in patients with familial hypercholesterolemia. N Engl J Med 1990;322: 1494-1499.

Shah M, Adams-Huet B, Garg A: Effect of highcarbohydrate or high-cis-monounsaturated fat diets on blood pressure: a meta-analysis of intervention trials. Am J Clin Nutr 2007; 85:1251-1256.

Siri-Tarino PW, Williams PT, Fernstrom HS, Rawlings RS, Krauss RM: Reversal of Small, Dense LDL Subclass Phenotype by Normalization of Adiposity. Obesity (Silver Spring) 2009, E-pub ahead of print.

- Sundram K, Hayes KC, Siru OH: Dietary palmitic acid results in lower serum cholesterol than does a lauric-myristic acid combination in normolipemic humans. Am J Clin Nutr 1994;59:841-846.

Sundram K, Ismail A, Hayes KC, Jeyamalar R, Pathmanathan R: Trans (elaidic) fatty acids adversely affect the lipoprotein profile relative to specific saturated fatty acids in humans. J Nutr 1997;127:514S-520S.

-Sundram K, Karupaiah T, Hayes KC: Stearic acid-rich interesterified fat and trans-rich fat raise the LDL/HDL ratio and plasma glucose relative to palm olein in humans. Nutr Metab (Lond) 2007;4:3.

Tardy AL, Lambert-Porcheron S, MalpuechBrugère C, et al: Dairy and industrial sources of trans fat do not impair peripheral insulin sensitivity in overweight women. Am J Clin Nutr 2009;90:88-94.

Terai M, Ohishi M, Ito N, et al: Comparison of arterial functional evaluations as a predictor of cardiovascular events in hypertensive patients: the Non-Invasive Atherosclerotic Evaluation in Hypertension (NOAH) study. Hypertens Res 2008;31:1135-1145.

Theobald HE, Chowienczyk PJ, Whittall R, Humphries SE, Sanders TA: LDL cholesterol-raising effect of low-dose docosahexaenoic acid in middle-aged men and women. Am J Clin Nutr 2004;79:558-563.

Theobald HE, Goodall AH, Sattar N, Talbot DC, Chowienczyk PJ, Sanders TA: Low-dose docosahexaenoic acid lowers diastolic blood pressure in middle-aged men and women. J Nutr 2007;137:973-978.

Tholstrup T, Miller GJ, Bysted A, Sandström B: Effect of individual dietary fatty acids on postprandial activation of blood coagulation factor VII and fibrinolysis in healthy young men. Am J Clin Nutr 2003;77:11251132 . 
Tholstrup T, Sandström B, Bysted A, Hølmer G: Effect of 6 dietary fatty acids on the postprandial lipid profile, plasma fatty acids, lipoprotein lipase, and cholesterol ester transfer activities in healthy young men. Am J Clin Nutr 2001;73:198-208.

- Tomiyama H, Takazawa K, Osa S, et al: Do eicosapentaenoic acid supplements attenuate age-related increases in arterial stiffness in patients with dyslipidemia? A preliminary study. Hypertens Res 2005;28:651-655.

Ueshima H, Stamler J, Elliott P, et al: Food omega-3 fatty acid intake of individuals (total, linolenic acid, long-chain) and their blood pressure: INTERMAP study. Hypertension 2007;50:313-319.

-Vartiainen E, Jousilahti P, Alfthan G, Sundvall J, Pietinen P, Puska P: Cardiovascular risk factor changes in Finland, 1972-1997. Int J Epidemiol 2000;29:49-56.

Vedin I, Cederholm T, Freund LY, et al: Effects of docosahexaenoic acid-rich n-3 fatty acid supplementation on cytokine release from blood mononuclear leukocytes: the OmegAD study. Am J Clin Nutr 2008;87:16161622.
Vessby B, Unsitupa M, Hermansen K, et al: Substituting dietary saturated for monounsaturated fat impairs insulin sensitivity in healthy men and women: the KANWU Study. Diabetologia 2001;44:312-319.

-Vogel RA, Corretti MC, Plotnick GD: Effect of a single high-fat meal on endothelial function in healthy subjects. Am J Cardiol 1997;79: 350-354.

Vogel RA, Corretti MC, Plotnick GD: The postprandial effect of components of the Mediterranean diet on endothelial function. J Am Coll Cardiol 2000;36:1455-1460.

Weggemans RM, Zock PL, Katan MB: Dietary cholesterol from eggs increases the ratio of total cholesterol to high-density lipoprotein cholesterol in humans: a meta-analysis. Am J Clin Nutr 2001;73:885-891.

-Whitlock G, Lewington S, Sherliker P, et al: Body-mass index and cause-specific mortality in 900000 adults: collaborative analyses of 57 prospective studies. Lancet 2009;373: 1083-1096.

Wu K, Bowman R, Welch AA, et al: Apolipoprotein E polymorphisms, dietary fat and fibre, and serum lipids: the EPIC Norfolk study. Eur Heart J 2007;28:2930-2936.

-Yamada T, Strong JP, Ishii T, et al: Atherosclerosis and omega-3 fatty acids in the populations of a fishing village and a farming village in Japan. Atherosclerosis 2000;153:469-481.
Yeboah J, Crouse JR, Hsu FC, Burke GL, Herrington DM: Brachial flow-mediated dilation predicts incident cardiovascular events in older adults: the Cardiovascular Health Study. Circulation 2007;115:2390-2397.

Yu-Poth S, Zhao G, Etherton T, Naglak M, Jonnalagadda S, Kris-Etherton PM: Effects of the National Cholesterol Education Program's Step I and Step II dietary intervention programs on cardiovascular disease risk factors: a meta-analysis. Am J Clin Nutr 1999; 69:632-646.

Zampelas A, Peel AS, Gould BJ, Wright J, Williams CM: Polyunsaturated fatty acids of the n-6 and n-3 series: effects on postprandial lipid and apolipoprotein levels in healthy men. Eur J Clin Nutr 1994;48:842-848.

Zhang J, Ping W, Chunrong W, Shou CX, Keyou G: Nonhypercholesterolemic effects of a palm oil diet in Chinese adults. J Nutr 1997; 127:509S-513S.

Zock PL, de Vries JH, de Fouw NJ, Katan MB: Positional distribution of fatty acids in dietary triglycerides: effects on fasting blood lipoprotein concentrations in humans. Am J Clin Nutr 1995;61:48-55. 